\title{
Epigenetic Alterations Associated With Early Prenatal Dexamethasone Treatment
}

\author{
Leif Karlsson, ${ }^{1}$ Michela Barbaro, ${ }^{2,3}$ Ewoud Ewing, ${ }^{4}$ David Gomez-Cabrero, ${ }^{5,6,7 *}$ \\ and Svetlana Lajic ${ }^{1 *}$
}

\begin{abstract}
${ }^{1}$ Department of Women's and Children's Health, Karolinska Institutet, Paediatric Endocrinology Unit (Q2:08), Karolinska University Hospital, SE-171 76 Stockholm, Sweden; ${ }^{2}$ Department of Molecular Medicine and Surgery, Karolinska Institutet, Karolinska University Hospital, SE-171 76 Stockholm, Sweden; ${ }^{3}$ Center for Inherited Metabolic Diseases (CMMS L7:05), Karolinska University Hospital, SE17176 Stockholm, Sweden; ${ }^{4}$ Department of Clinical Neuroscience, Centre for Molecular Medicine, Karolinska Institutet (L8:05), Karolinska University Hospital, SE-171 76 Stockholm, Sweden; ${ }^{5}$ Unit for Computational Medicine, Karolinska Institutet (L8:05), Karolinska University Hospital, SE-171 76 Stockholm, Sweden; ${ }^{6}$ Mucosal and Salivary Biology Division, King's College, London Dental Institute, London SE1 9RT, United Kingdom; and ${ }^{7}$ Translational Bioinformatics Unit, NavarraBiomed, Complejo Hospitalario de Navarra (CHN), Universidad Pública de Navarra (UPNA), IdiSNA, Pamplona, 31008, Navarra, Spain
\end{abstract}

ORCiD numbers: 0000-0001-6274-9330 (L. Karlsson).

*D.G.-C. and S.L. contributed equally to this study.

\begin{abstract}
Prenatal treatment with dexamethasone (DEX) reduces virilization in girls with congenital adrenal hyperplasia (CAH). It has potential short- and long-term risks and has been shown to affect cognitive functions. Here, we investigate whether epigenetic modification of DNA during early developmental stages may be a key mediating mechanism by which prenatal DEX treatment could result in poor outcomes in the offspring. We analyzed genome-wide $\mathrm{CD}^{+} \mathrm{T}$ cell DNA methylation, assessed using the Infinium HumanMethylation450 BeadChip array in 29 individuals (mean age $=16.4 \pm 5.9$ years) at risk for CAH and treated with DEX during the first trimester and 37 population controls (mean age $=17.0$ years, $\mathrm{SD}=$ 6.1 years). We identified 9672 differentially methylated probes (DMPs) associated with DEX treatment and 7393 DMPs associated with a DEX $\times$ sex interaction. DMPs were enriched in intergenic regions located near epigenetic markers for active enhancers. Functional enrichment of DMPs was mostly associated with immune functioning and inflammation but also with nonimmune-related functions. DEX-associated DMPs enriched near single nucleotide polymorphisms (SNPs) associated with inflammatory bowel disease, and DEX $\times$ sex-associated DMPs enriched near SNPs associated with asthma. DMPs in genes involved in the regulation and maintenance of methylation and steroidogenesis were identified as well. Methylation in the $B D N F$, FKBP5, and NR3C1 genes were associated with the performance on several Wechsler Adult Intelligence Scale-Fourth Edition subscales. In conclusion, this study indicates that DNA methylation is altered after prenatal DEX treatment. This finding may have implications for the future health of the exposed individual.
\end{abstract}

Copyright (C) 2019 Endocrine Society

This article has been published under the terms of the Creative Commons Attribution NonCommercial, No-Derivatives License (CC BY-NC-ND; https://creativecommons.org/licenses/by-nc$\mathrm{nd} / 4.0 /$ ).

Freeform/Key Words: prenatal treatment, dexamethasone, methylation, epigenetics, fetal programming, congenital adrenal hyperplasia

Abbreviations: CAH, congenital adrenal hyperplasia; DEX, dexamethasone; DMP, differentially methylated probe; FDR, falsediscovery rate; GAT, Genetic Association Test; GO, gene ontology; GREAT, Genomic Regions Enrichment of Annotations Tool; GWAS, genome-wide association studies; IBD, inflammatory bowel disease; PNMS, prenatal maternal stress; SNP, single nucleotide polymorphism; WAIS-IV, Wechsler Adult Intelligence Scale-Fourth Edition. 
The synthetic glucocorticoid dexamethasone (DEX) has been used for several decades to ameliorate prenatal virilization of girls with classic congenital adrenal hyperplasia $(\mathrm{CAH})$, an inborn error of cortisol synthesis. Girls with $\mathrm{CAH}$ are treated during the entire gestational period from week 7 , whereas treatment in boys with CAH and in healthy children is stopped when the genotype of the fetus is known (gestational weeks 12 to 14) [1]. We have previously identified substantial negative effects of DEX on verbal working memory in children not having $\mathrm{CAH}$ and who were treated during the first trimester of fetal life [2,3]. These effects seem to be sex dimorphic, as cognitive deficits were more pronounced in treated girls [3]. Furthermore, women with $\mathrm{CAH}$ and treated during the entire gestational period perform worse on several cognitive tasks than women with CAH not treated prenatally [4].

Early-life glucocorticoid treatment or stressful events are good examples of fetal programming factors, as they have been associated with short- and long-term adverse effects on human health [5]. For example, antenatal glucocorticoid treatment in preterm infants resulted in increased aortic arch stiffness and altered glucose metabolism in early adulthood [6], as well as altered stress reactivity [7]. Another consequence is cortical thinning in general and in particular, of the rostral anterior cingulate cortex [8]. Thickness of the left rostral anterior cingulate cortex was further associated with more affective problems [8].

Furthermore, studies on children subjected to prenatal maternal stress (PNMS) during a natural disaster identified prenatal stress as a programming factor that may lead to longlasting consequences for immunity [9]. Additionally, exposure to PNMS was positively associated with higher insulin levels and higher body mass index during adolescence [10]. At $5 \frac{1}{2}$ years of age, children exposed to high levels of objective stress had deficits in cognitive abilities [11]. Finally, PNMS was associated with functionally organized changes in the T cell methylome with specific changes in gene programming of the immune system itself [12].

Here, we investigate whether DNA methylation is altered after prenatal glucocorticoid treatment. We hypothesize that epigenetic modification of DNA during early developmental stages may be a key mediating mechanism by which prenatal DEX treatment could result in poor outcomes in the offspring. We investigated whether prenatal DEX treatment generates long-lasting effects on $\mathrm{CpG}$ methylation profiles. To this end, we isolated $\mathrm{CD} 4^{+} \mathrm{T}$ cells from children and adults at risk for $\mathrm{CAH}$, but not having $\mathrm{CAH}$, and exposed to DEX during the first trimester of fetal life. Data on whole-genome DNA methylation in DEX-exposed cases were compared with data from untreated population controls.

\section{Patients and Methods}

\section{A. Subjects}

The study is part of a longitudinal project evaluating prenatal treatment of CAH in a total of 237 individuals in Sweden (for details, see Wallensteen et al. [3]). Here, we focus on the effects of firsttrimester DEX treatment on whole-genome methylation in prenatally treated subjects without CAH compared with healthy, untreated controls from the Swedish general population. Written, informed consent was obtained from all participants, and the study was approved by the Regional Ethics Committee of Stockholm. In total, 66 subjects [29 DEX-treated subjects (mean age = 16.4 years, $\mathrm{SD}=5.9$ years), 12 young women and 17 young men, and 37 population controls (mean age $=17.0$ years, $\mathrm{SD}=6.1$ years $), 18$ young women and 19 young men] were included.

\section{B. Isolation of T Cells and Flow Cytometry}

Peripheral blood mononuclear cells were separated by density centrifugation from $50 \mathrm{ml}$ of whole blood per subject. $\mathrm{CD} 4^{+} \mathrm{T}$ cells were isolated from peripheral blood mononuclear cells using magnetic-activated cell sorting (Miltenyi Biotec) and stored at $-80^{\circ} \mathrm{C}$.

The purity of $\mathrm{CD} 4^{+}$cell populations was evaluated by immunophenotyping using two-color antibody panels. Data were acquired and analyzed using the Cyan ADP Analyzer (Summit 
4.3; Beckman Coulter). T Cell population purity was $94.9 \%$ (SD 3.1). For a more detailed description of $\mathrm{T}$ cell isolation and flow cytometry, see Reinius et al. [13].

\section{DNA Extraction, Bisulfite Treatment, and DNA Methylation Measurements Using the 450K BeadChip Array}

Genomic DNA was isolated from T cell pellets using the QiAmp DNA Mini Kit (Qiagen), according to the manufacturer's instructions. The DNA concentration was measured using the Qubit 2.0 concentration (Thermo Fisher Scientific). Bisulfite treatment was performed using the EZ-96 DNA Methylation Kit (Zymo Research), and DNA methylation measurements were performed using the Infinium HumanMethylation450 BeadChip array (Illumina).

\section{Differential Methylation Analysis}

The data analysis was performed in $\mathrm{R}$, and preprocessing was conducted using the lumi package $[14,15]$. Five samples, three controls, and two treated subjects were dropped during the qualitycontrol phase as a result of poor genome-wide correlation with other samples and an aberrant distribution of $\beta$ values. In addition, the following probes were excluded from the analysis: (i) probes located on the $\mathrm{Y}$ and $\mathrm{X}$ chromosomes; (ii) probes with a single nucleotide polymorphism (SNP) located within $3 \mathrm{bp}$ of the interrogated CpG site to exclude false-positive probes caused by genetic variations; and (iii) $\mathrm{CpG}$ probes with detection values of $P>0.01$ [16].

After filtering, 395,462 probes were included in the differential analysis. Estimations of $\beta$ values for the probes were performed using a previously described, three-step pipeline [17]. Batch effects were identified using a principal component analysis and subsequently corrected using the Combat function from the Surrogate Variable Analysis (sva) Bioconductor package [18]. Differential DNA methylation was computed by transforming $\beta$ values into M values and using the Linear Models for Microarray Data (limma) package to define a linear model, including the following variables: DEX, age, sex, and the interaction of the treatment (DEX) with the sex of the subject (DEX $\times$ sex) $[15,19]$. The interaction between treatment and sex was studied as a result of previous results, indicating a sex-dimorphic effect of DEX treatment [3]. For the DEX-derived differential methylation analysis, we identified three sets of relevant $\mathrm{CpG}$ sites: probes with (i) $p_{\text {uncorrected }}<0.01$, (ii)

$p_{\text {uncorrected }}<0.01$ and a group difference in methylation of $5 \%$, and (iii) $p_{\text {uncorrected }}<0.01$ and a group difference in methylation of $10 \%$. Similar lists were computed for the DEX $\times$ sex interaction.

\section{D-1. Association between DNA methylation and cognitive performance}

We also sought to investigate whether there would be associations between methylation ( $\beta$ values) in a subset of candidate genes with biological relevance for brain function and cognitive outcome. To this end, we related methylation in differentially methylated probes (DMPs) from the candidate genes BDNF, NR3C1, NR3C2, and FKBP5 to the cognitive performance of the participants. For a detailed description of the procedures and tests used for assessment of cognitive performance, see Karlsson et al. [20]. Here, the test scores (of subjects 16 years of age or older) that estimate general intelligence [Wechsler Adult Intelligence Scale-Fourth Edition (WAIS-IV), "Matrices" and "Vocabulary"], executive functions (WAIS-IV, " Coding," "Digit Span," "Span Board," and the Stroop test), and learning and memory (WAIS-IV, "List learning") were analyzed using multiple linear regression with $\beta$ values from DMPs in the BDNF, NR3C1, NR3C2, and FKBP5 genes as predictors, together with age, sex, and $\beta \times$ sex.

\section{E. Functional Enrichment}

\section{E-1. GREAT analysis}

To investigate the functional relevance of DEX-associated methylation changes, the Genomic Regions Enrichment of Annotations Tool (GREAT; version 3.0.0; http://bejerano.stanford. 
edu/great) was applied [21]. Functional enrichment of DMPs was performed for DEX and DEX $\times$ sex-associated DMPs and running separate analyses for the three lists of differential methylated probes described in Fig. 1A. Gene sets with a false-discovery rate (FDR) $<0.05$ were considered significant and selected. To avoid threshold-driven results, enriched gene sets from all analyses were subsequently overlapped, and a gene ontology (GO) term was considered to be enriched if it appeared to be significant in at least two gene-set enrichment analyses.

\section{E-2. Enrichment analysis of disease susceptibility loci}

With the purpose of evaluating whether altered states of DNA methylation increase susceptibility to disease, we investigated if DMPs $(P<0.01)$ were enriched at disease- associated

A)

CpG probe data acquired after Quality Control 395,462 probes; 20140 genes

\begin{tabular}{|c|c|c|c|c|}
\hline \multicolumn{2}{|c|}{$\begin{array}{l}\text { Differential Methylation [DEX] } \\
\qquad p<0.01 \text { : }\end{array}$} & \multicolumn{2}{|c|}{$\begin{array}{l}\text { Differential Methylation [DEX x sex] } \\
\qquad p<0.01 \text { : }\end{array}$} & \multirow{2}{*}{$\begin{array}{c}\text { Overlap [DEX + DEX } \\
\text { x sex] }\end{array}$} \\
\hline 9672 CpG sites & 5220 genes & 7393 CpG sites & 4421 genes & \\
\hline $\begin{array}{l}\text { Hypermethylated } \\
\text { CpG sites: } 3482\end{array}$ & $\begin{array}{l}\text { Hypomethylated } \\
\text { CpG sites: } 6190\end{array}$ & $\begin{array}{l}\text { Hypermethylated } \\
\text { CpG sites: } 3129\end{array}$ & $\begin{array}{l}\text { Hypomethylated } \\
\text { CpG sites: } 4264\end{array}$ & \\
\hline \multicolumn{2}{|c|}{$p<0.01+6$-value $>5 \%:$} & \multicolumn{2}{|c|}{$p<0.01$ 6-value $>5 \%$ : } & Overlap \\
\hline 2234 CpG sites & 1422 genes & 2786 CpG sites & 1749 genes & 776 CpG sites \\
\hline $\begin{array}{l}\text { Hypermethylated } \\
\text { CpG sites: } 519\end{array}$ & $\begin{array}{l}\text { Hypomethylated } \\
\text { CpG sites: } 1715\end{array}$ & $\begin{array}{l}\text { Hypermethylated } \\
\text { CpG sites: } 1613\end{array}$ & $\begin{array}{l}\text { Hypomethylated } \\
\text { CpG sites: } 1173\end{array}$ & \\
\hline \multicolumn{2}{|c|}{$p<0.016$-value $>10 \%$} & \multicolumn{2}{|c|}{$p<0.01$ 6-value $>10 \%$} & Overlap \\
\hline $42 \mathrm{CpG}$ sites & 24 genes & 200 CpG sites & 159 genes & $11 \mathrm{CpG}$ sites \\
\hline $\begin{array}{l}\text { Hypermethylated } \\
\text { CpG sites: } 19\end{array}$ & $\begin{array}{l}\text { Hypomethylated } \\
\text { CpG sites: } 23\end{array}$ & $\begin{array}{l}\text { Hypermethylated } \\
\text { CpG sites: } 89\end{array}$ & $\begin{array}{l}\text { Hypomethylated } \\
\text { CpG sites: } 111\end{array}$ & \\
\hline
\end{tabular}

B)
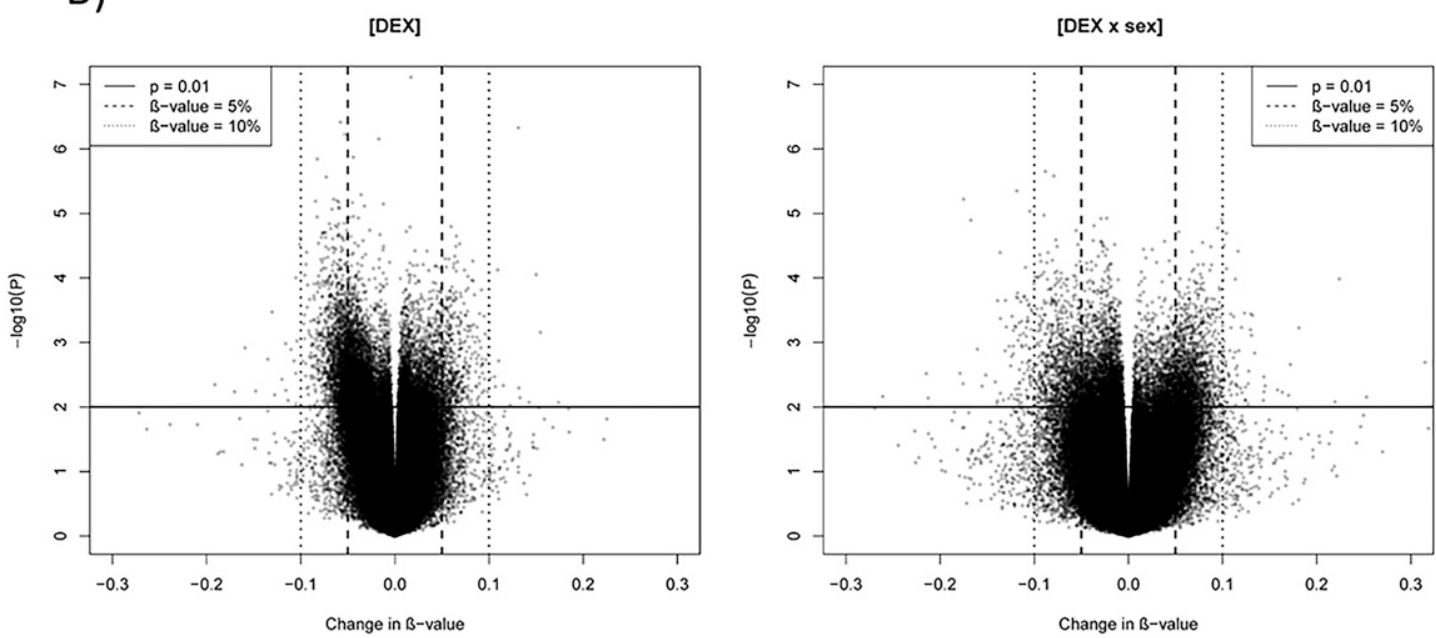

Figure 1. Overview of the differential methylation analysis. (A) Overview of the differential methylation analysis showing results for the effect of DEX and DEX $\times$ sex interaction. Number of DMPs in total, hyperhypomethylated, and unique genes is shown for the three levels of analysis. (B) Scatter plots showing $-\log 10(\mathrm{p})$ and $\beta$ values for all analyzed CpG sites in the $450 \mathrm{~K}$ array for the effect of DEX (left) and for the interaction between DEX and sex (right). 
SNPs identified in genome-wide association studies (GWAS; https://www.ebi.ac.uk/gwas/). We focused on a set of inflammatory and autoimmune disorders, where a programming effect for altered disease susceptibility as a result of DEX treatment could be plausible. These were asthma, pulmonary function, inflammatory bowel disease (IBD), ulcerative colitis, and rheumatoid arthritis. We also included a set of the following negative-control SNPs associated with terms unlikely to be affected by DEX: colorectal cancer, migraine, major depressive disorder, age-related macular degeneration, mean platelet volume, and iron status biomarkers. For each one of these 11 sets, we also computed a negative control set consisting of common SNPs acquired from the online University of California Santa Cruz SNP database (dbSNP; v.147; https://genome.ucsc.edu/). These sets were selected by matching each SNP with the CpG probe density of the SNP from the GWAS sets and thereby controlling for the number of SNPs included and for CpG probe density. Enrichment was computed using the Genetic Association Test (GAT) in four genomic bins: 1, 2, 5, and $10 \mathrm{~kb}$ around DMPs and SNPs [22]. Enrichments with an FDR $<0.05$ were considered significant.

\section{F. Validation by Bisulfite Pyrosequencing}

Bisulfite pyrosequencing was used to validate the $450 \mathrm{~K}$ array. The selected CpGs were cg16280132 and cg26348243, located in the LTA gene and cg02322400 in the MAML2 gene. Methods and primers are available upon request.

\section{Results}

\section{A. Differential Methylation Analysis}

\section{A-1. Genome-wide methylation analysis}

In this study, we aimed to identify alterations in DNA methylation to find evidence for fetal epigenetic reprogramming after prenatal glucocorticoid treatment. Three levels of differential methylation associated with the DEX treatment and the DEX $\times$ sex interaction were investigated. We conducted the analysis in this manner on the basis of the following assumptions: (i) most differences in methylation between DEX-treated subjects and controls would be mild; (ii) we investigated a large number of probes that required multiple testing otherwise; (iii) our aim was to determine the biological impact of DEX on methylation level. An overview of the results from the differential methylation analyses is given in Fig. 1 . The majority of the group differences, for the DEX and the DEX $\times$ sex-associated DMPs, was between $0 \%$ and $10 \%$ in magnitude (Fig. 1A). DEX $\times$ sex-associated DMPs had more hypomethylated probes (53.5\%) than hypermethylated probes (46.5\%) when investigating all analyzed sites (Fig. 1B). The percentages for DEX alone were $50.3 \%$ for hypermethylated probes and $49.7 \%$ for hypomethylated probes.

After correction for multiple comparisons, the distribution of the DMPs revealed an enrichment of them in gene bodies and intergenic regions in relation to the nearest gene (all values, $P<0.05$ ) and in open seas in relation to the nearest $\mathrm{CpG}$ island (all values, $P<0.05$; Fig. 2). In addition, DEX $\times$ sex-associated DMPs enriched in south shelves $<2 \mathrm{~kb}$, flanking outward from a CpG shore $(P<0.05$; Fig. 2$)$. The pattern of probe distributions was similar for all probe outputs [23].

\section{A-2. Overlap with epigenetic features}

As enrichment of DMPs was identified both in gene bodies and in intergenic regions, we aimed to identify a mechanism by which these sites could potentially affect gene regulation. Therefore, we overlapped the probes that have a substantial change in methylation of at least $10 \%$ and that were located within intergenic regions or gene bodies with genomic regions enriched for the histone modifications H3K4me1 and H3K27ac (enriched at active enhancers) 
Region in relation to nearest genes

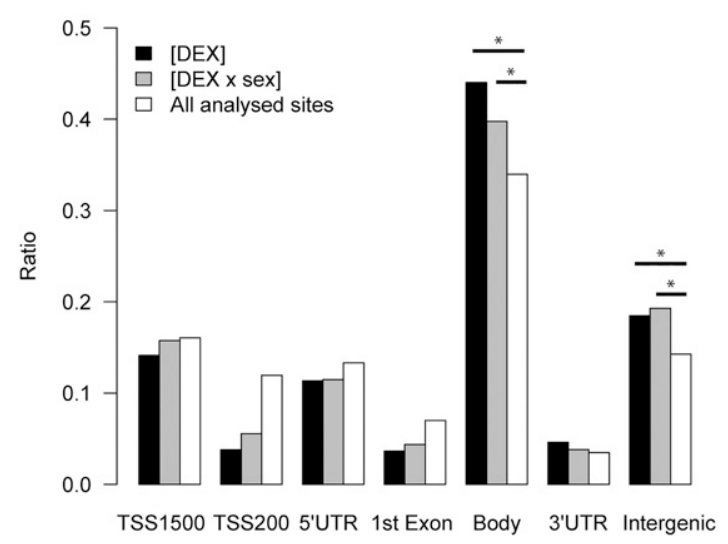

Region in relation to $\mathrm{CpG}$ island

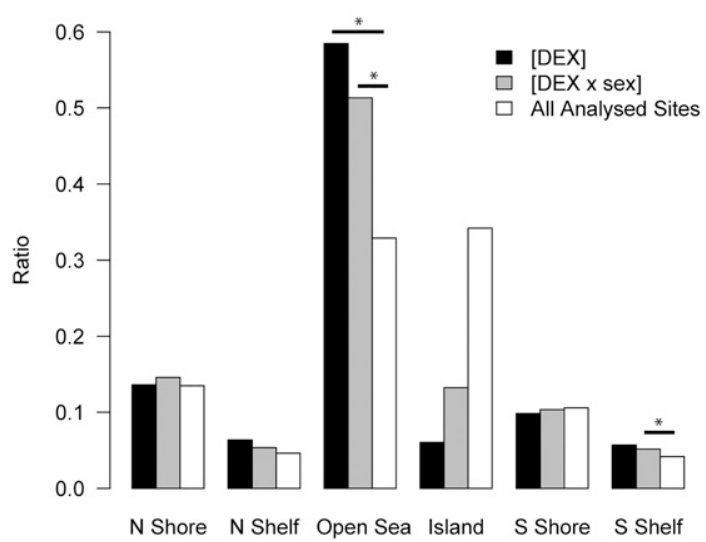

Figure 2. Location of differentially methylated $\mathrm{CpG}$ sites. Probe locations in relation to the nearest gene or genes (left), as well as their location in relation to the nearest CpG island (right). Ratios are shown for probes with the selection criteria of an absolute change in methylation of $5 \%$ and $P<0.01$. The overall distribution of important $\mathrm{CpG}$ sites compared with all analyzed sites on the Infinium HumanMethylation450 BeadChip was analyzed using a Fisher exact test (Bonferroni corrected), ${ }^{*} P<0.05$. N, north; S, south; UTR, untranslated region.

or H3K36me (enriched in actively transcribed gene bodies). In addition, all probes, regardless of the location, were overlapped with DNase 1 hypersensitive sites, i.e., sites of uncondensed chromatin. DMPs were analyzed compared with the proportion of overlapping probes included in the $450 \mathrm{~K}$ array using Fisher's exact test. The proportion of probes in intergenic regions and associated with the DEX $\times$ sex interaction was significantly higher than expected for H3K4me1 sites (odds ratio $=2.84, P=0.0004$ ) and for H3K27ac sites (odds ratio $=2.54, P=$ 0.002). Genomic locations for markers were acquired from the Roadmap Epigenomics Project (http://egg2.wustl.edu/roadmap/web_portal/).

\section{A-3. Targeted analyses of candidate genes}

Furthermore, we wanted to investigate subsets of targeted genes from previous DNA methylation studies, targeting similar or close systems, to see whether we could replicate their results. We analyzed a subset of genes specifically reported to be differentially methylated in individuals exposed to high glucocorticoid/stress levels [12, 24-28] (Table 1). We also investigated other clinically/biologically relevant genes involved in the regulation and maintenance of DNA methylation, per se (Table 2), as well as genes involved in steroid action, regulation, and production (Table 3). All genes were analyzed independently on the $450 \mathrm{~K}$ array, and CpG probes located within the gene or $1500 \mathrm{bp}$, up- or downstream, were evaluated. We identified DMPs in the majority of the targeted gene sets; results are presented in Tables 1-3.

\section{A-4. Association between methylation and cognitive performance}

We investigated whether methylation in DMPs in the BDNF, NR3C1, NR3C2, and the FKBP5 genes was associated with cognitive performance, assessed with the WAIS-IV and the Stroop tests [29]. These genes were chosen for this analysis as a result of their biological relevance for brain function and the fact that they all contained DMPs. In the BDNF gene, $\beta$ values of two CpGs (cg10558494 and cg23947039) and their interaction with sex were associated with performance during the working memory task Digit Span and the learning and memory task List learning (immediate recall; all values, $P<0.05$ ). Furthermore, $\beta$ values in $\operatorname{cg} 06025631$ and their interaction with sex were associated with performance during the 
Table 1. Summary of the Analysis Targeting Candidate Genes

\begin{tabular}{|c|c|c|c|c|c|c|c|c|}
\hline \multirow[b]{2}{*}{ Gene } & \multicolumn{3}{|c|}{ DEX } & \multicolumn{2}{|c|}{ DEX $\times$ Sex } & \multicolumn{3}{|c|}{ Data From the Literature } \\
\hline & $\begin{array}{c}\text { No. of } \\
\text { Important } \\
\text { Probes }\end{array}$ & $\begin{array}{c}\text { Probe } \\
\text { Location }\end{array}$ & $\begin{array}{l}\text { Direction of } \\
\text { Change in } \\
\text { Methylation }\end{array}$ & $\begin{array}{c}\text { No. of } \\
\text { Important } \\
\text { Probes }\end{array}$ & $\begin{array}{l}\text { Probe } \\
\text { Location }\end{array}$ & Tissue & Cohort & Reference \\
\hline$B D N F$ & 2 & $\begin{array}{l}\text { TSS1500; } \\
\text { TSS200; } \\
\text { 5'UTR; } \\
\text { body }\end{array}$ & Hypermethylation & 2 & $\begin{array}{l}\text { TSS1500; } \\
\text { TSS200; } \\
\text { 5'UTR; body; } \\
\text { first exon }\end{array}$ & $\begin{array}{l}\text { Peripheral } \\
\text { blood cells }\end{array}$ & $\begin{array}{l}\text { Major } \\
\quad \text { depression }\end{array}$ & {$[24]$} \\
\hline HSD211B2 & 1 & Body & Hypermethylation & 1 & Body & Placenta & Newborns & [28] \\
\hline$N R 3 C 1$ & 2 & $\begin{array}{c}\text { TSS1500; } \\
5^{\prime} \text { UTR }\end{array}$ & Hypermethylation & 1 & $5^{\prime}$ UTR & $\begin{array}{l}\text { Cord blood and } \\
\text { maternal } \\
\text { blood }\end{array}$ & $\begin{array}{l}\text { Maternal } \\
\text { depression }\end{array}$ & {$[26]$} \\
\hline $\mathrm{NR} 3 \mathrm{C} 2$ & 1 & $5^{\prime} \mathrm{UTR}$ & Hypermethylation & 1 & $5^{\prime} \mathrm{UTR}$ & N.A. & N.A. & - \\
\hline FKBP5 & 3 & $\begin{array}{c}\text { TSS1500; } \\
5^{\prime} \text { UTR }\end{array}$ & Hypermethylation & 3 & $\begin{array}{c}\text { TSS1500; } \\
5^{\prime} \text { UTR }\end{array}$ & $\begin{array}{l}\text { Peripheral } \\
\text { blood cells }\end{array}$ & $\begin{array}{c}\text { Childhood } \\
\text { trauma }\end{array}$ & [25] \\
\hline LTA & 3 & $\begin{array}{l}\text { TSS1500; } \\
\text { body }\end{array}$ & Hypermethylation & 6 & $\begin{array}{l}\text { TSS1500; } \\
\text { TSS200; } \\
\text { 5'UTR; first } \\
\text { exon }\end{array}$ & $\mathrm{CD}^{+} \mathrm{T}$ cells & $\begin{array}{l}\text { PNMS } \\
\quad \text { exposure }\end{array}$ & {$[12]$} \\
\hline$T N F$ & 9 & $\begin{array}{l}\text { TSS1500; } \\
\text { first exon; } \\
\text { body; } \\
\text { 3'UTR }\end{array}$ & Hypermethylation & 4 & $\begin{array}{l}\text { TSS1500; } \\
\text { first exon; } \\
3^{\prime} \text { UTR }\end{array}$ & N.A. & N.A. & - \\
\hline SCG5 & 2 & $5^{\prime} \mathrm{UTR}$ & Hypermethylation & 2 & $5^{\prime} \mathrm{UTR}$ & $\mathrm{CD}^{+} \mathrm{T}$ cells & $\begin{array}{l}\text { PNMS } \\
\quad \text { exposure }\end{array}$ & {$[12]$} \\
\hline$S L C 6 A 4$ & 1 & Body & Hypermethylation & 1 & Body & $\begin{array}{l}\mathrm{T} \text { Cells and } \\
\text { monocytes }\end{array}$ & $\begin{array}{l}\text { Childhood } \\
\text { aggression }\end{array}$ & {$[27]$} \\
\hline
\end{tabular}

For each gene, the number of important probes, their location, and the direction of change in methylation are presented. Probes were analyzed in a linear model, including age and sex as covariates. Significance was defined as an uncorrected $P<0.05$. NR3C2 and $T N F$ were not identified in the literature but were included as candidate genes as a result of their biological roles relative to the candidate genes NR3C1 and LTA.

processing speed task Coding (both $P<0.05$ ). In the FKBP5 gene, $\beta$ values and their interaction with sex for cg14642437 were associated with performance on the task measuring fluid intelligence Matrices (both $P<0.05$ ). In the NR3C1 gene, $\beta$ values in cg18068240 associated with performance in Matrices, as well as in the task-assessing ability to inhibit an overlearned response, "The Stroop color and word test" (both $P<0.05$ ). The interaction between $\beta$ values and sex was also significantly associated with Matrices $(P=0.047)$.

\section{B. Functional Enrichment}

\section{B-1. GREAT analysis}

To add functional relevance, an enrichment analysis of DMPs was performed for GO terms in "Biological processes," "Molecular functions," and "Cellular components," using the annotation tool GREAT. In total, 31 different GO terms were significantly enriched for either an association with DEX or for an association with DEX $\times$ sex $($ FDR $<0.05)$ [29]. Enriched ontologies are summarized in Fig. 3. The majority of the enriched GO terms relates to immune functioning and inflammation, e.g., "interleukin 1 production and secretion" and "T cell receptor complex." However, there are enriched terms related to biological functions unrelated to the functionality of the $\mathrm{T}$ cell, indicating an effect on multiple biological systems.

\section{B-2. Enrichment analysis of disease susceptibility loci}

GAT was used to investigate whether the DMPs enrich with disease risk SNPs from the GWAS catalog. Results for all enrichments are described [23]. Overall, the significance of the 
Table 2. Summary of the Analysis Targeting Candidate Genes Involved With the Regulation of DNA Methylation

\begin{tabular}{|c|c|c|c|c|c|c|}
\hline Gene & Probe ID & Location & $P[\mathrm{DEX}]$ & $\beta[\mathrm{DEX}]$ & $P[$ DEX $\times$ Sex $]$ & $\beta[\mathrm{DEX} \times$ Sex $]$ \\
\hline$D N M T 1$ & cg21892967 & TSS1500 & 0.007 & -0.02 & 0.511 & 0.01 \\
\hline$D N M T 1$ & $\operatorname{cg} 01347596$ & Body & 0.038 & 0.01 & 0.005 & -0.02 \\
\hline$D N M T 1$ & $\operatorname{cg} 15043801$ & TSS200 & 0.147 & -0.01 & 0.034 & 0.01 \\
\hline$D N M T 1$ & cg07058526 & Body & 0.232 & 0.01 & 0.036 & -0.02 \\
\hline DNMT3A & cg23042148 & Body & 0.005 & 0.04 & 0.034 & -0.04 \\
\hline DNMT3A & $\operatorname{cg} 10239163$ & Body & 0.000 & 0.07 & 0.010 & -0.07 \\
\hline DNMT3A & cg23903708 & Body & 0.002 & 0.04 & 0.003 & -0.06 \\
\hline DNMT3A & cg00050692 & Body & 0.002 & -0.06 & 0.054 & 0.05 \\
\hline DNMT3A & $\operatorname{cg} 15150970$ & Body & 0.005 & 0.03 & 0.025 & -0.03 \\
\hline DNMT3A & $\operatorname{cg} 15843262$ & Body & 0.061 & 0.03 & 0.025 & -0.04 \\
\hline DNMT3A & $\operatorname{cg} 17137500$ & $5^{\prime} \mathrm{UTR}$ & 0.061 & 0.01 & 0.014 & -0.02 \\
\hline DNMT3A & cg19256292 & $5^{\prime} \mathrm{UTR}$ & 0.088 & 0.01 & 0.037 & -0.02 \\
\hline DNMT3A & cg26544247 & Body & 0.098 & 0.02 & 0.027 & -0.04 \\
\hline DNMT3A & cg23393100 & Body & 0.145 & 0.00 & 0.023 & -0.01 \\
\hline DNMT3A & cg10270719 & $5^{\prime} \mathrm{UTR}$ & 0.197 & 0.00 & 0.022 & -0.01 \\
\hline DNMT3B & $\operatorname{cg} 13636640$ & TSS1500 & 0.014 & 0.04 & 0.057 & -0.05 \\
\hline DNMT3B & cg22052056 & 5'UTR & 0.067 & 0.02 & 0.147 & -0.02 \\
\hline DNMT3B & cg09835408 & $5^{\prime} \mathrm{UTR}$ & 0.092 & 0.03 & 0.028 & -0.05 \\
\hline DNMT3L & cg26398867 & Body & 0.016 & 0.01 & 0.057 & -0.01 \\
\hline TET1 & cg02774862 & $5^{\prime} \mathrm{UTR}$ & 0.029 & 0.03 & 0.041 & -0.03 \\
\hline TET1 & $\operatorname{cg} 14506140$ & Body & 0.073 & 0.00 & 0.023 & 0.01 \\
\hline TET1 & $\operatorname{cg} 15254238$ & $5^{\prime} \mathrm{UTR}$ & 0.106 & 0.02 & 0.027 & -0.05 \\
\hline TET2 & $\operatorname{cg} 12306086$ & $5^{\prime} \mathrm{UTR}$ & 0.007 & 0.05 & 0.010 & -0.07 \\
\hline TET2 & cg20586654 & $5^{\prime} \mathrm{UTR}$ & 0.500 & 0.00 & 0.030 & -0.01 \\
\hline TET2 & $\operatorname{cg} 11508949$ & TSS200 & 0.887 & 0.00 & 0.023 & -0.01 \\
\hline TET2 & cg09295382 & $5^{\prime}$ UTR; first exon & 0.332 & 0.00 & 0.008 & 0.01 \\
\hline TET3 & $\operatorname{cg} 13808088$ & $3^{\prime} \mathrm{UTR}$ & 0.140 & 0.01 & 0.013 & -0.01 \\
\hline$K D M 1 A$ & cg26662347 & TSS200 & 0.035 & 0.00 & 0.044 & -0.01 \\
\hline$K D M 1 B$ & cg00102920 & TSS1500; 5'UTR & 0.044 & 0.00 & 0.170 & 0.00 \\
\hline$K D M 1 B$ & $\operatorname{cg} 07465480$ & TSS1500; 5'UTR & 0.258 & 0.00 & 0.021 & 0.01 \\
\hline
\end{tabular}

The probe locations and the direction of change in methylation are shown for probes importantly associated with the prenatal DEX treatment or with the DEX $\times$ sex interaction. Probes were analyzed in a linear model, including age and sex as covariates. Significance was defined as an uncorrected $P<0.05$. Significant results are marked in boldface. Abbreviation: ID, identification.

colocalization increased with an increase in the size of the genomic bin. This is expected, as an increased bin size results in more overlaps between DMPs and SNPs. Here, we focus on the results from enrichment at $2 \mathrm{~kb}$, as it has been shown that most CpGs are influenced by SNPs within a 2 -kb range [30]. In the 2 -kb bin, after FDR correction, DMPs associated with DEX show enrichment around IBD-associated SNPs $(q=0.022)$ and DEX $\times$ sex-associated probes enriched with asthma-associated SNPs $(q=0.022$; Fig 4$)$. The enrichment for IBD and asthma was substantial in all genomic bins analyzed $(q<0.05)$ [23]. No controls were enriched in the 2 -kb bin (all $q>0.05)$.

\section{Validation With Bisulfite Pyrosequencing}

Results for five CpGs, located in the LTA and MAML2 genes, were replicated using bisulfite pyrosequencing. The directions of the changes in methylation corresponded to the changes seen with the Illumina $450 \mathrm{~K}$ array for the $\mathrm{CD} 4^{+} \mathrm{T}$ cells (Table 4).

\section{Discussion}

To find evidence of long-lasting fetal programming effects after prenatal glucocorticoid treatment, we investigated DNA methylation in children at risk for, but not having, CAH, 
Table 3. Summary of the Analysis Targeting Candidate Genes Involved With Regulation of Adrenal Steroidogenesis

\begin{tabular}{llccccc}
\hline Gene & Probe ID & Location & $\boldsymbol{P}[$ DEX] & $\boldsymbol{\beta}[$ DEX] & $\boldsymbol{P}[$ DEX $\times$ Sex] & $\boldsymbol{\beta}[$ DEX $\times$ Sex $]$ \\
\hline CRH & cg19035496 & TSS200 & $\mathbf{0 . 0 2 0}$ & $\mathbf{- 0 . 0 4}$ & $\mathbf{0 . 0 4 7}$ & $\mathbf{0 . 0 5}$ \\
CRH & cg08215831 & TSS200 & 0.072 & -0.03 & $\mathbf{0 . 0 1 8}$ & $\mathbf{0 . 0 5}$ \\
CRHR1 & cg27410679 & Body & $\mathbf{0 . 0 0 8}$ & $\mathbf{- 0 . 0 5}$ & $\mathbf{0 . 0 3 1}$ & $\mathbf{0 . 0 6}$ \\
CYP11A1 & cg24482024 & TSS1500 & $\mathbf{0 . 0 0 9}$ & $\mathbf{- 0 . 0 3}$ & $\mathbf{0 . 0 3 9}$ & $\mathbf{0 . 0 3}$ \\
CYP11A1 & cg18068537 & TSS200 & $\mathbf{0 . 0 4 4}$ & $\mathbf{- 0 . 0 3}$ & 0.065 & 0.04 \\
CYP11A1 & cg06285340 & First exon; TSS1500 & $\mathbf{0 . 0 1 0}$ & $\mathbf{- 0 . 0 5}$ & $\mathbf{0 . 0 2 3}$ & $\mathbf{0 . 0 6}$ \\
CYP11A1 & cg03449379 & 3'UTR & $\mathbf{0 . 0 1 0}$ & $\mathbf{- 0 . 0 4}$ & 0.196 & 0.03 \\
CYP11A1 & cg22186216 & Body; 5'UTR & $\mathbf{0 . 0 3 1}$ & $\mathbf{- 0 . 0 3}$ & 0.065 & 0.04 \\
CYP11A1 & cg24578679 & Body; TSS200 & $\mathbf{0 . 0 1 2}$ & $\mathbf{0 . 0 1}$ & $\mathbf{0 . 0 4 0}$ & $\mathbf{- 0 . 0 1}$ \\
CYP11A1 & cg02916102 & First exon; body; 5'UTR & 0.118 & 0.01 & $\mathbf{0 . 0 2 9}$ & $\mathbf{- 0 . 0 2}$ \\
CYP11A1 & cg16332610 & First exon; body; 5'UTR & 0.213 & 0.01 & $\mathbf{0 . 0 3 6}$ & $\mathbf{- 0 . 0 2}$ \\
CYP11B1 & cg20073007 & Body & $\mathbf{0 . 0 1 1}$ & $\mathbf{- 0 . 0 3}$ & $\mathbf{0 . 0 0 7}$ & $\mathbf{0 . 0 5}$ \\
CYP11B1 & cg05416055 & Body & $\mathbf{0 . 0 4 4}$ & $\mathbf{- 0 . 0 3}$ & $\mathbf{0 . 0 4 5}$ & $\mathbf{0 . 0 5}$ \\
CYP11B1 & cg17015994 & TSS200 & $\mathbf{0 . 0 0 2}$ & $\mathbf{- 0 . 0 5}$ & $\mathbf{0 . 0 0 5}$ & $\mathbf{0 . 0 6}$ \\
CYP11B1 & cg21298978 & TSS200 & $\mathbf{0 . 0 0 7}$ & $\mathbf{- 0 . 0 4}$ & $\mathbf{0 . 0 2 9}$ & $\mathbf{0 . 0 5}$ \\
CYP11B2 & cg11324259 & TSS200 & $\mathbf{0 . 0 0 4}$ & $\mathbf{- 0 . 0 4}$ & $\mathbf{0 . 0 3 3}$ & $\mathbf{0 . 0 5}$ \\
CYP11B2 & cg07954324 & TSS200 & $\mathbf{0 . 0 1 9}$ & $\mathbf{- 0 . 0 3}$ & 0.108 & 0.03 \\
CYP19A1 & cg01916429 & 5'UTR & $\mathbf{0 . 0 1 0}$ & $\mathbf{- 0 . 0 2}$ & $\mathbf{0 . 0 0 6}$ & $\mathbf{0 . 0 3}$ \\
CYP19A1 & cg19946085 & 5'UTR & $\mathbf{0 . 0 2 2}$ & $\mathbf{0 . 0 1}$ & $\mathbf{0 . 0 0 5}$ & $\mathbf{- 0 . 0 1}$ \\
CYP21A2 & cg04771084 & TSS200 & 0.560 & -0.01 & $\mathbf{0 . 0 2 6}$ & $\mathbf{0 . 0 7}$ \\
SRD5A2 & cg04900872 & Body & $\mathbf{0 . 0 0 2}$ & $\mathbf{- 0 . 0 5}$ & $\mathbf{0 . 0 1 2}$ & $\mathbf{0 . 0 5}$ \\
\hline Th
\end{tabular}

The location and the direction of change in methylation are shown for probes importantly associated with prenatal DEX treatment or with the DEX $\times$ sex interaction. Probes were analyzed in a linear model, including age and sex as covariates. Significance was defined as an uncorrected $P<0.05$. Significant results are marked in boldface.

who were treated with DEX during the first trimester of fetal life. The prenatal treatment of CAH presents a dilemma, as the majority of the treated cases is subjected to a potentially harmful therapy without any benefit. This type of therapy therefore requires an adequate risk-benefit analysis and a long-term follow-up of treated cases.

We choose the $\mathrm{T}$ cell as a model system, as it is easily accessible, and the first trimester DEX treatment affects the fetus during a period of gestation (gestation weeks 7 to 12) when the fetal thymus is formed, and the first lymphocyte gene rearrangements occur [31]. The $\mathrm{T}$ cell can be used to study the effects on this cell type per se but also as a model system for studying mechanisms or events that may occur in other cell types during embryogenesis after glucocorticoid exposure [32]. The sample size of our study is relatively small with a risk of detecting false positives. The study describes the epigenetic alterations from prenatal glucocorticoid treatment in humans. To evaluate how these alterations affect the health of treated individuals requires studies on larger cohorts, in addition to functional studies.

The genome-wide analysis revealed substantial differential methylation associated with prenatal DEX treatment, and in addition, the DEX effects were modified by sex. DEX $\times$ sexassociated probes also included more hypomethylated probes than hypermethylated ones. DMPs were enriched in gene bodies and intergenic regions. DMPs, located in intergenic regions and associated with the DEX $\times$ sex interaction, enrich with marks enriched for the specific histone modifications H3K4me1 and H3K27ac, i.e., markers of active enhancers. This suggests that changes in methylation associated with prenatal DEX treatment may affect the gene regulation through alterations of the chromatin state and thereby change the accessibility of regulatory elements in the genome. This is reinforced by the results from the functional enrichment analysis with GREAT, where DEX-associated probes are enriched for the GO term, "histone displacement" (Fig. 3). These data are in line with data from studies in rats, where prenatal DEX treatment decreased the production of proinflammatory cytokines, along with decreased signs of active chromatin (acetylation of histone 3 lysines, H3K4me1/3, and H3K36me3) in the promotor region of the TNF- $\alpha$ gene [33]. TNF- $\alpha$ contained DMPs in our study (Table 1). 


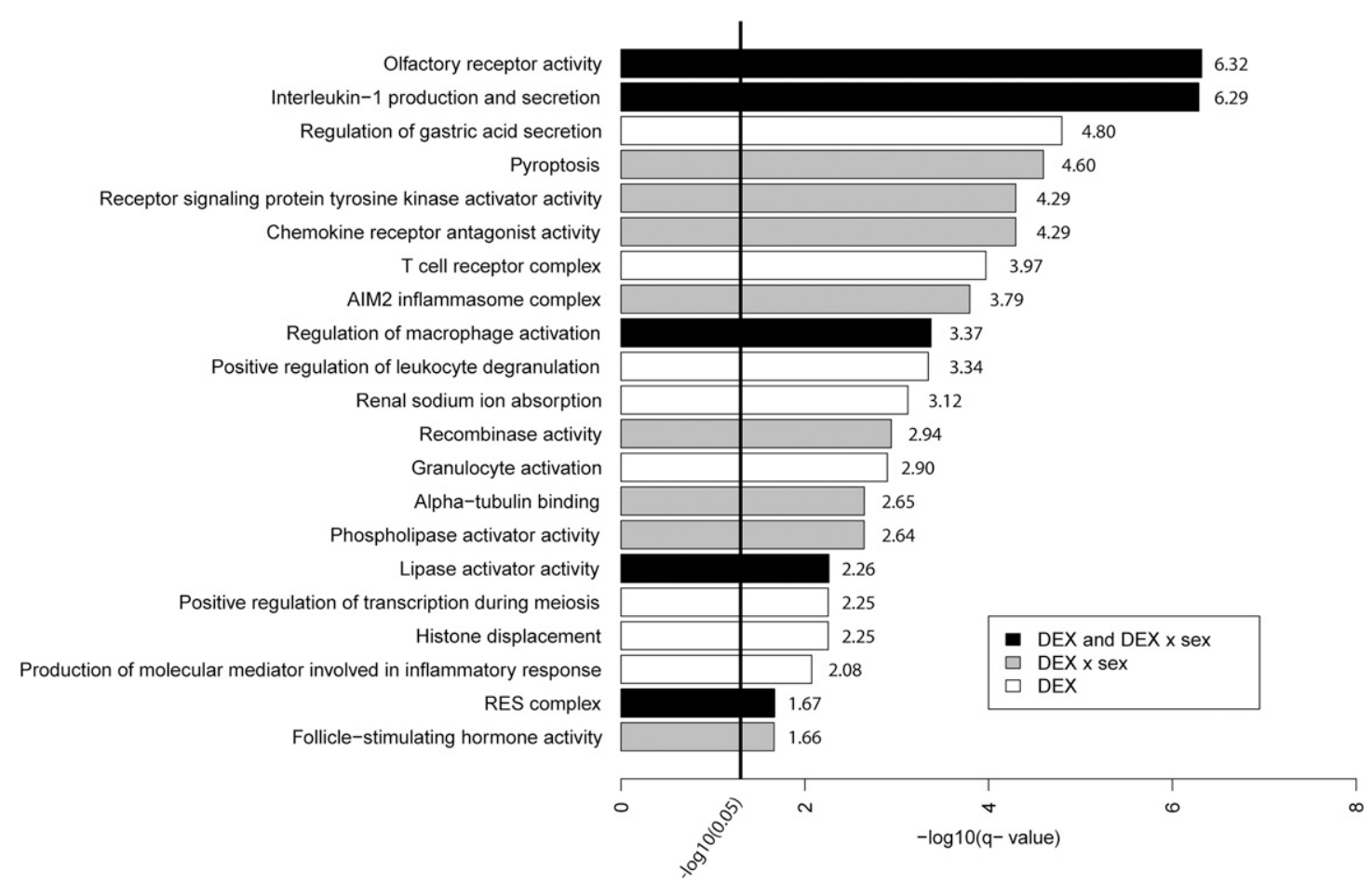

Figure 3. Summary of enriched GO terms. Summary of enriched GO terms significantly associated with the DEX treatment (white) and DEX $\times$ sex interaction (gray) or both (black). GO terms from the same biological pathway and that had overlapping probes are clustered together in a single bar with the lowest $-\log 10$ ( $q$ value) available for the specific cluster. The bold line indicates significance threshold after FDR correction. AIM2, absent in melanoma 2; RES, retention and splicing.

Functional enrichment of the DMPs further revealed that the changes in DNA methylation in the $\mathrm{T}$ cell were functionally organized, especially regarding immune functioning and inflammation. We were able to show that DMPs were enriched near disease-related SNPs for IBD and asthma. This raises the possibility that when DEX alters DNA methylation in cis, it could contribute to the development of these disorders by altering gene expression. A consequence of prenatal DEX exposure may therefore be that the treatment creates a longlasting program for altered immunity, which could potentially lead to development of immune-mediated inflammatory disease.

The results presented here are in line with the aforementioned Canadian study investigating long-term effects associated with PNMS. T Cell DNA methylation was found to correlate with the levels of cytokines in the blood of the offspring [34]. The altered cytokine levels were subsequently attributed to a shift in the levels of T helper 1 cells toward T helper 2 cells [9, 34]. Moreover, higher levels of PNMS predicted a greater lifetime risk of wheezing and asthma. These effects were only observed in girls and suggest that maternal distress/ glucocorticoid treatment during pregnancy affects fetal programming of the immune system and that these effects may be sex dimorphic [35].

In our targeted analysis, we identified DMPs in genes involved in the regulation and maintenance of DNA methylation (Table 2). This suggests that DEX treatment interferes with certain parts of the epigenetic regulatory system. Through this mechanism, it may have more widespread and long-lasting effects on gene regulation. These results are in line with studies in guinea pigs, where prenatal treatment with betamethasone was associated with altered expression of genes involved in the regulation and maintenance of DNA methylation per se [36].

We further identified several DMPs located upstream of the transcriptional start site region (TSS200, promotor regions) in genes involved in adrenal steroidogenesis (Table 3). 
A)

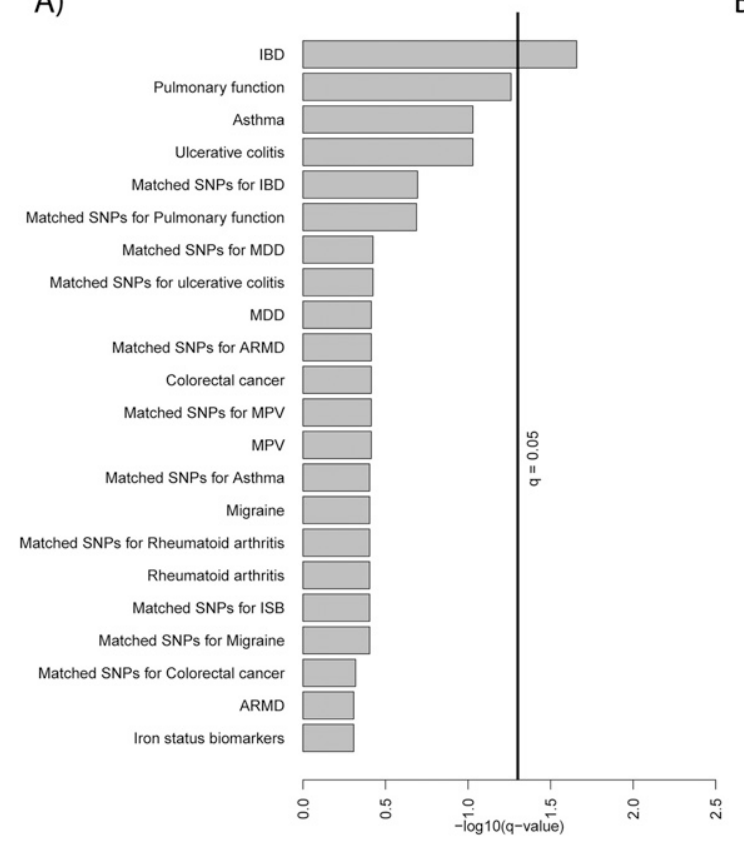

B)

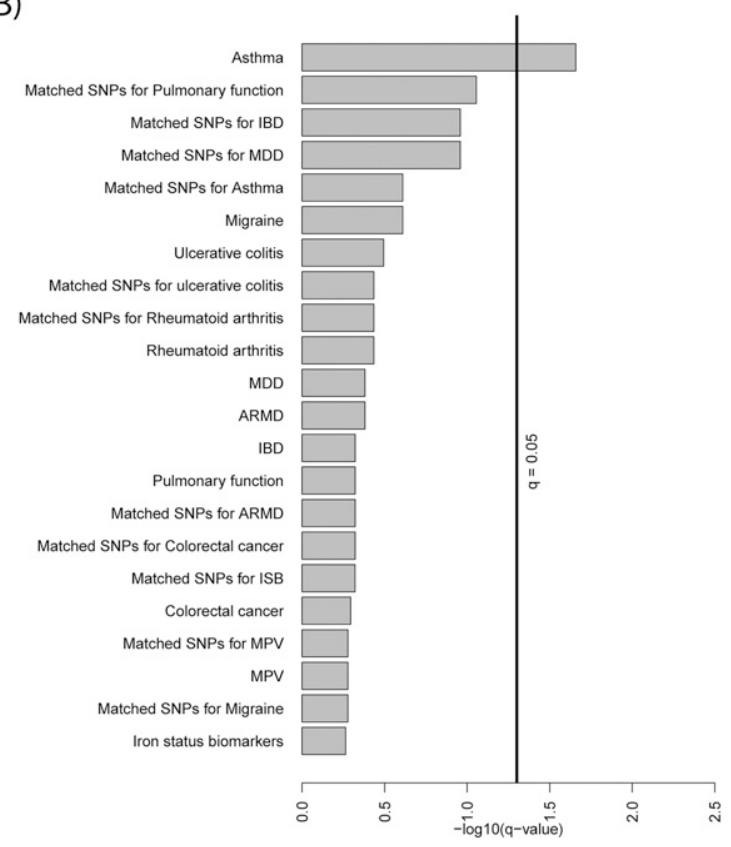

Figure 4. Enrichment results from the GAT. Results from the GAT: (A) effects of DEX; (B) effects of the DEX $\times$ sex. Overlaps were computed with $2 \mathrm{~kb}$ genomic bins of the $\mathrm{CpG}$ probes $(P<0.01)$ and $2 \mathrm{~kb}$ bins genomic bins of the SNPs. The bold lines indicate significance threshold after FDR correction. ARMD, age-related macular degeneration; ISB, iron status biomarker; MDD, major depressive disorder; MPV, mean platelet volume.

This may reflect an adaptation of the hypothalamic-pituitary-adrenal axis on the genomic level as a response to prenatal DEX treatment.

With regard to genes identified in the literature and being affected by glucocorticoids, stress, and traumatic events, all investigated genes contained DMPs (Table 1). Furthermore, in genes relevant for the central nervous system, we found important associations between DNA methylation in BDNF, NR3C1, and FKBP5 and performance in cognitive tasks [29]. We have previously identified deficits in executive functions in individuals exposed to DEX during the first trimester [2,3]. The mechanism for these DEX-induced deficits is not known, but a link between epigenetic alterations in specific neurons and in cells involved in the function of the hypothalamic-pituitary-adrenal axis may be part of the answer.

Table 4. Methylation Data for Validated CpG Sites

\begin{tabular}{|c|c|c|c|c|c|}
\hline & \multirow{2}{*}{$\begin{array}{c}\text { MAML2 } \\
\begin{array}{c}\text { Pos. } 1 \\
(\operatorname{cg} 02322400)\end{array}\end{array}$} & \multicolumn{4}{|c|}{$L T A$} \\
\hline & & $\begin{array}{c}\text { Pos. 1 } \\
(\operatorname{cg} 16280132)\end{array}$ & $\begin{array}{c}\text { Pos. 2 } \\
(\operatorname{cg26348243)}\end{array}$ & Pos. 3 & Pos. 4 \\
\hline \multicolumn{6}{|c|}{ 450K Array (T cells) } \\
\hline DEX (\%) & $47.4(9.9)$ & $20.9(5.5)$ & $13.1(7.0)$ & - & - \\
\hline Control (\%) & $42.1(8.8)$ & $17.2(7.0)$ & $7.0(7.1)$ & - & - \\
\hline$P[\mathrm{DEX}]$ & $3.33 \mathrm{e}-07$ & 0.007 & 0.011 & - & - \\
\hline \multicolumn{6}{|c|}{ Pyrosequencing ( $\mathrm{T}$ cells) } \\
\hline $\operatorname{DEX}(\%)$ & $32.9(6.7)$ & $16.5(9.7)$ & $16.4(7.8)$ & $12.1(7.4)$ & $18.4(8.7)$ \\
\hline Control (\%) & $28.1(7.5)$ & $8.8(11.2)$ & $9.6(9.4)$ & $6.0(9,1)$ & $10.2(11.5)$ \\
\hline$P[\mathrm{DEX}]$ & $1.39 \mathrm{E}-05$ & 0.023 & 0.042 & 0.066 & 0.013 \\
\hline
\end{tabular}

Results from the $450 \mathrm{~K}$ array and from the c nucleotide. Methylation at interrogated CpG sites in $\mathrm{T}$ cells showed a similar state in the $450 \mathrm{~K}$ array as in the bisulfite pyrosequencing. 


\section{Conclusion}

Here, we show associations between DNA methylation and first-trimester DEX treatment in treated subjects. The effects are moderated by sex and may change gene regulation by alterations in the state of chromatin. The effect of DEX on T cell DNA methylation is mostly related to immune functioning and inflammation and may therefore potentially program long-lasting effects on immunity and subsequently, lead to development of immunerelated disorders.

How the identified alterations affect the health of the individual require studies on larger cohorts, in addition to functional studies.

In conclusion, this study indicates that prenatal DEX treatment affects fetal epigenetic programming, and together with the added cognitive risks, we recommend that the protocol for prenatal treatment of $\mathrm{CAH}$ should be revised to avoid treatment of healthy fetuses.

\section{Acknowledgments}

Financial Support: This study was supported by Marianne and Marcus Wallenbergs Stiftelse, International Fundraising for Congenital Adrenal Hyperplasia/European Society for Pediatric Endocrinology, Stockholms Liety for Peng, and Svenska Läkaresällskapet (to S.L.) and Stiftelsen Frimurare Barnhuset i Stockholm, Stiftelsen Samariten, Stiftelsen Sven Jerrings Fond, Sällskapet Barnavård, and Wera Ekstret BStiftelse för Pediatrisk Forskning (to L. K.).

Correspondence: Svetlana Lajic, MD, PhD, Department of Women's and Children's Health, Pediatric Endocrinology Unit, Karolinska vägen 37A (QB83), Karolinska University Hospital, SE-171 76 Stockholm, Sweden. E-mail: Svetlana.Lajic@ki.se.

Disclosure Summary: The authors have nothing to disclose.

\section{References and Notes}

1. Lajic S, Nordenström A, Hirvikoski T. Long-term outcome of prenatal dexamethasone treatment of 21-hydroxylase deficiency. Endocr Dev. 2011;20:96-105.

2. Hirvikoski T, Nordenström A, Lindholm T, Lindblad F, Ritzén EM, Wedell A, Lajic S. Cognitive functions in children at risk for congenital adrenal hyperplasia treated prenatally with dexamethasone. J Clin Endocrinol Metab. 2007;92(2):542-548.

3. Wallensteen L, Zimmermann M, Thomsen Sandberg M, Gezelius A, Nordenström A, Hirvikoski T, Lajic S. Sex-dimorphic effects of prenatal treatment with dexamethasone. J Clin Endocrinol Metab. 2016; 101(10):3838-3846.

4. Karlsson L, Gezelius A, Nordenström A, Hirvikoski T, Lajic S. Cognitive impairment in adolescents and adults with congenital adrenal hyperplasia. Clin Endocrinol (Oxf). 2017;87(6):651-659.

5. Lewis AJ, Austin E, Knapp R, Vaiano T, Galbally M. Perinatal maternal mental health, fetal programming and child development. Healthcare (Basel). 2015;3(4):1212-1227.

6. Kelly BA, Lewandowski AJ, Worton SA, Davis EF, Lazdam M, Francis J, Neubauer S, Lucas A, Singhal A, Leeson P. Antenatal glucocorticoid exposure and long-term alterations in aortic function and glucose metabolism. Pediatrics. 2012;129(5):e1282-e1290.

7. Alexander N, Rosenlöcher F, Stalder T, Linke J, Distler W, Morgner J, Kirschbaum C. Impact of antenatal synthetic glucocorticoid exposure on endocrine stress reactivity in term-born children. J Clin Endocrinol Metab. 2012;97(10):3538-3544.

8. Davis EP, Sandman CA, Buss C, Wing DA, Head K. Fetal glucocorticoid exposure is associated with preadolescent brain development. Biol Psychiatry. 2013;74(9):647-655.

9. Veru F, Dancause K, Laplante DP, King S, Luheshi G. Prenatal maternal stress predicts reductions in CD4+ lymphocytes, increases in innate-derived cytokines, and a Th2 shift in adolescents: Project Ice Storm. Physiol Behav. 2015;144:137-145.

10. Dancause KN, Veru F, Andersen RE, Laplante DP, King S. Prenatal stress due to a natural disaster predicts insulin secretion in adolescence. Early Hum Dev. 2013;89(9):773-776.

11. Laplante DP, Brunet A, Schmitz N, Ciampi A, King S. Project Ice Storm: prenatal maternal stress affects cognitive and linguistic functioning in 5 1/2-year-old children. J Am Acad Child Adolesc Psychiatry. 2008;47(9):1063-1072. 
12. Cao-Lei L, Massart R, Suderman MJ, Machnes Z, Elgbeili G, Laplante DP, Szyf M, King S. DNA methylation signatures triggered by prenatal maternal stress exposure to a natural disaster: Project Ice Storm. PLoS One. 2014;9(9):e107653.

13. Reinius LE, Acevedo N, Joerink M, Pershagen G, Dahlén SE, Greco D, Söderhäll C, Scheynius A, Kere J. Differential DNA methylation in purified human blood cells: implications for cell lineage and studies on disease susceptibility. PLoS One. 2012;7(7):e41361.

14. Du P, Kibbe WA, Lin SM. lumi: a pipeline for processing Illumina microarray. Bioinformatics. 2008; 24(13):1547-1548.

15. Du P, Zhang X, Huang CC, Jafari N, Kibbe WA, Hou L, Lin SM. Comparison of Beta-value and M-value methods for quantifying methylation levels by microarray analysis. BMC Bioinformatics. 2010;11(1): 587.

16. Nordlund J, Bäcklin CL, Wahlberg P, Busche S, Berglund EC, Eloranta ML, Flaegstad T, Forestier E, Frost BM, Harila-Saari A, Heyman M, Jónsson ÓG, Larsson R, Palle J, Rönnblom L, Schmiegelow K, Sinnett D, Söderhäll S, Pastinen T, Gustafsson MG, Lönnerholm G, Syvänen AC. Genome-wide signatures of differential DNA methylation in pediatric acute lymphoblastic leukemia. Genome Biol. 2013;14(9):r105.

17. Marabita F, Almgren M, Lindholm ME, Ruhrmann S, Fagerström-Billai F, Jagodic M, Sundberg CJ, Ekström TJ, Teschendorff AE, Tegnér J, Gomez-Cabrero D. An evaluation of analysis pipelines for DNA methylation profiling using the Illumina HumanMethylation450 BeadChip platform. Epigenetics. 2013;8(3):333-346.

18. Leek JT, Johnson WE, Parker HS, Jaffe AE, Storey JD. The sva package for removing batch effects and other unwanted variation in high-throughput experiments. Bioinformatics. 2012;28(6):882-883.

19. Ritchie ME, Phipson B, Wu D, Hu Y, Law CW, Shi W, Smyth GK. limma powers differential expression analyses for RNA-sequencing and microarray studies. Nucleic Acids Res. 2015;43(7):e47.

20. Karlsson L, Nordenström A, Hirvikoski T, Lajic S. Prenatal dexamethasone treatment in the context of at risk CAH pregnancies: long-term behavioral and cognitive outcome. Psychoneuroendocrinology. 2018;91:68-74.

21. McLean CY, Bristor D, Hiller M, Clarke SL, Schaar BT, Lowe CB, Wenger AM, Bejerano G. GREAT improves functional interpretation of cis-regulatory regions. Nat Biotechnol. 2010;28(5):495-501.

22. Heger A, Webber C, Goodson M, Ponting CP, Lunter G. GAT: a simulation framework for testing the association of genomic intervals. Bioinformatics. 2013;29(16):2046-2048.

23. Karlsson L, Barbaro M, Ewing E, Gomez-Cabrero D, Lajic S. Epigenetic alterations associated with early prenatal dexamethasone treatment: Supplementary Figure 1 \& 2. figshare 2018. Accessed 16 August 2018. http://doi.org/10.6084/m9.figshare.6974312.v1.

24. Fuchikami M, Morinobu S, Segawa M, Okamoto Y, Yamawaki S, Ozaki N, Inoue T, Kusumi I, Koyama T, Tsuchiyama K, Terao T. DNA methylation profiles of the brain-derived neurotrophic factor (BDNF) gene as a potent diagnostic biomarker in major depression. PLoS One. 2011;6(8):e23881.

25. Klengel T, Mehta D, Anacker C, Rex-Haffner M, Pruessner JC, Pariante CM, Pace TW, Mercer KB, Mayberg HS, Bradley B, Nemeroff CB, Holsboer F, Heim CM, Ressler KJ, Rein T, Binder EB. Allelespecific FKBP5 DNA demethylation mediates gene-childhood trauma interactions. Nat Neurosci. 2013; 16(1):33-41.

26. Oberlander TF, Weinberg J, Papsdorf M, Grunau R, Misri S, Devlin AM. Prenatal exposure to maternal depression, neonatal methylation of human glucocorticoid receptor gene (NR3C1) and infant cortisol stress responses. Epigenetics. 2008;3(2):97-106.

27. Wang D, Szyf M, Benkelfat C, Provençal N, Turecki G, Caramaschi D, Côté SM, Vitaro F, Tremblay RE, Booij L. Peripheral SLC6A4 DNA methylation is associated with in vivo measures of human brain serotonin synthesis and childhood physical aggression. PLoS One. 2012;7(6):e39501.

28. Marsit CJ, Maccani MA, Padbury JF, Lester BM. Placental 11-beta hydroxysteroid dehydrogenase methylation is associated with newborn growth and a measure of neurobehavioral outcome. PLoS One. 2012;7(3):e33794.

29. Karlsson L, Barbaro M, Ewing E, Gomez-Cabrero D, Lajic S. Epigenetic alterations associated with early prenatal dexamethasone treatment: Supplementary Table $1 \& 2$. figshare 2018. Accessed 16 August 2018. http://doi.org/10.6084/m9.figshare.6974285.v1.

30. Liu Y, Li X, Aryee MJ, Ekström TJ, Padyukov L, Klareskog L, Vandiver A, Moore AZ, Tanaka T, Ferrucci L, Fallin MD, Feinberg AP. GeMes, clusters of DNA methylation under genetic control, can inform genetic and epigenetic analysis of disease. Am J Hum Genet. 2014;94(4):485-495.

31. Veru F, Laplante DP, Luheshi G, King S. Prenatal maternal stress exposure and immune function in the offspring. Stress. 2014;17(2):133-148. 
32. Ma B, Wilker EH, Willis-Owen SA, Byun HM, Wong KC, Motta V, Baccarelli AA, Schwartz J, Cookson WO, Khabbaz K, Mittleman MA, Moffatt MF, Liang L. Predicting DNA methylation level across human tissues. Nucleic Acids Res. 2014;42(6):3515-3528.

33. Yu HR, Kuo HC, Chen CC, Sheen JM, Tiao MM, Chen YC, Chang KA, Tain YL, Huang LT. Prenatal dexamethasone exposure in rats results in long-term epigenetic histone modifications and tumour necrosis factor- $\alpha$ production decrease. Immunology. 2014;143(4):651-660.

34. Cao-Lei L, Veru F, Elgbeili G, Szyf M, Laplante DP, King S. DNA methylation mediates the effect of exposure to prenatal maternal stress on cytokine production in children at age 13(1/2) years: Project Ice Storm. Clin Epigenetics. 2016;8:54.

35. Turcotte-Tremblay AM, Lim R, Laplante DP, Kobzik L, Brunet A, King S. Prenatal maternal stress predicts childhood asthma in girls: Project Ice Storm. Biomed Res Int. 2014;2014:201717.

36. Crudo A, Petropoulos S, Moisiadis VG, Iqbal M, Kostaki A, Machnes Z, Szyf M, Matthews SG. Prenatal synthetic glucocorticoid treatment changes DNA methylation states in male organ systems: multigenerational effects. Endocrinology. 2012;153(7):3269-3283. 